\title{
Efficacy of Sodium Valproate and Olanzapine in treating bipolar affective disorder 'mania'at a tertiary care hospital in Nepal: A comparative study Chaurasia L ${ }^{* 1}$, Shah $\mathrm{SK}^{2}$, Chetty SM ${ }^{3}$
}

\author{
College of Medical Sciences-Teaching Hospital, Bharatpur, Chitwan, Nepal
}

${ }^{1}$ Assistant Prof., Department of Pharmacology, Janaki Medical College, Janakpur, Nepal.
${ }^{2}$ Associate Prof., Department of Psychiatry, College of Medical Sciences-Teaching Hospital, Bharatpur, Chitwan, Nepal.
${ }^{3}$ Prof. \& HOD., Department of Pharmacology, College of Medical Sciences-Teaching Hospital, Bharatpur, Chitwan, Nepal.

ABSTRACT

Background and Objectives: Bipolar affective disorder, mania is the mood of an abnormally elevated arousal energy level or a state of heightened overall activation with enhanced affective expression together with lability of affect. The objective of the study was to compare the efficacy of sodium valproate and olanzapine in bipolar affective disorder, mania patients at a tertiary care hospital in Nepal

Material and Methods: A randomized observational prospective open label study was conducted for one and half year at College of Medical Sciences-Teaching Hospital (CMS-TH), Bharatpur, Nepal in the Psychiatry Department. Sixty patients diagnosed with bipolar affective disorder, mania were enrolled. 30 patients received sodium valproate and 30 patients received olanzapine. Patients were monitored and evaluated on baseline (day 0), day 7 and day 30 and compared to the baseline for the severity of illness using the 11-item Young Mania Rating Scale (YMRS).

Results: The mean baseline YMRS score for all cases on sodium valproate $(n=30)$ on day 0 was $38.87 \pm 3.73$, while it was reduced to $13.90 \pm 1.95(\mathrm{p}<0.001)$ on day 30. Similarly, the mean baseline YMRS score for all cases on olanzapine $(n=30)$ on day 0 was $40.83 \pm 6.50$, while it was reduced to $14.47 \pm 2.83$ ( $\mathrm{p}<0.001$ ) on day 30 .The mean decrease in YMRS score by sodium valproate was $64.24 \%$ and by olanzapine was $64.56 \%$.

Conclusion: Treatment with sodium valproate and olanzapine significantlyimproves the mean mania ratings score and there is no statistically significant difference in efficacy of both the drugs in patients diagnosed with bipolar affective disorder, mania.

Kev Words: Bipolar affective disorder, Mania, Olanzapine, Sodium Valproate

INTRODUCTION

Bipolar disorder (BPD) is a mood disorder that is characterized by periods of pathologic mood elevation (mania or hypomania) [1].The International Classification of Diseases-10 (ICD10) and Diagnostic and Statistical Manual-IV (DSM-IV) classifications consider mania as a 
uni-dimensional illness [2]. The illness is characterised by frequent episodes of relapse and/or recurrence and not much is known about factors that may precipitate new episodes [3]. According to World Health Organization (WHO), bipolar disorder is the sixth leading cause worldwide of disability-adjusted life years in individuals aged 15 to 44 years [4]. The typical period of bipolar disorder onset as a syndrome is between 16 and 24 years of age [5]. Bipolar spectrum disorders affect $0.1 \%$ of children and $1 \%$ of adolescents [6]. It accounts for a prevalence rate of $3.7 \%$ or higher [7].

Sign and symptoms of mania include: increased energy, activity and restlessness; excessively high, overly good, euphoric mood, extreme irritability, racing thoughts, talking very fast, jumping from one idea to another ,distractibility, cannot concentrate well, little sleep needed, unrealistic beliefs in one's abilities and powers, poor judgment, spending sprees, a lasting period of behavior that is different from usual, increased sexual drive, abuse of drugs (particularly cocaine, alcohol and sleeping medications), provocative, intrusive or aggressive behavior and denial that anything is wrong [8].

Sodium valproate has mood stabilizing action [9], whereas olanzapine is an atypical neuroleptic effective in treating both phases of bipolar disorder compared with placebo and as effective as established drug therapies [10]. It has actions on gamma amino butyric acid (GABA) and serotonin that is linked to antiaggression [11]. It is US Food and Drug Administration ( US FDA) approved for the treatment of acute manic episodes and its response rate in acute mania is around 50\%, compared to a placebo effect of $20-30 \%$ [12]. It lacks anticholinergic toxicity, has fewer extrapyramidal side effects, is associated with a minimal risk of tardive dyskinesia, lacks cardiac and respiratory side effects and has been reported to have better tolerability [13].

Olanzapine is a derivative and structural analogue of clozapine with a high affinity for dopaminergic $\left(D_{1}, D_{2}, D_{4}\right)$, serotonergic, muscarinic, histaminic and $\alpha_{1}$ adrenergic receptors. It is antagonistic at both the $\mathrm{D}_{2}$ and 5$\mathrm{HT}_{2 \mathrm{~A}}$ receptors [14]. It has a solid basis supporting its use in bipolar disorder [15]. Some of the side effects of olanzapine are weight gain, sedation, orthostatic hypotension and constipation.

Despite the introduction of many new mood stabilizing medications and a continually advancing understanding of their individual strengths and weaknesses, selecting the best possible treatment for each individual patient remains a significant challenge for general practitioners and psychiatrists. Therefore an attempt was made primarily to compare the efficacy of two mood stabilizers- sodium valproate and olanzapine using the Young Mania Rating Scale (YMRS) as the scale for assessment, which contains 11 items, four of which are scored $0-4$ and the remaining seven are scored from $0-8$, based on severity. The YMRS is designed as a 15 to 30 minute's interview administered by trained clinicians and is considered gold standard to which scale developers evaluate concurrent validity with newer scales. Limitations include the fact that there is no guideline to ensure standardized administration, no report of discriminant validity or test-retest reliability.

\section{MATERIAL AND METHODS}

The study was a randomized observational prospective open label study with two treatment group design conducted in patients diagnosed with bipolar affective disorder, mania 
visiting Department of Psychiatry of College of Medical Sciences - Teaching Hospital (CMS-TH), Bharatpur-10, Chitwan during the period of August 2013 to January 2015.

Demographic data were obtained from the patients/guardians after obtaining written informed consent. Patients between the ages 1875 years, diagnosed with clinical bipolar affective disorder mania, DSM-IV-TR Patient Version and with a minimum total score of 20 on the YMRS, at both the screening visit and on the day of random assignment to study groups (baseline) were selected. Pregnant and lactating women, patients with history of uncontrolled gastrointestinal, renal, hepatic, endocrine, cardiovascular, pulmonary, immunologic or hematologic disease, serious or unstable medical illness, history of severe drug allergy or hypersensitivity reactions to the study drugs, imminent risk of causing injury to themselves or others, DSM-IV substance dependence within the past 30 days (except nicotine or caffeine) were excluded.

All the patients were randomly divided into two treatment groups containing 30 patients in each group: Treatment Group 1 (TG1) who received sodium valproate (500 to $2500 \mathrm{mg}$ per day) and Treatment Group 2 (TG2) who received olanzapine (5 to $20 \mathrm{mg}$ per day). Sampling technique was simple random sampling. The doses of both the drugs to individual patient, assigned by the consulting Psychiatrist were based on sign and symptoms, clinical response, drug plasma levels and adverse events. These papers were used to randomly allocate the patient in 2 treatment groups at day 0 (baseline).

All the patients were randomly divided into two treatment groups containing 30 patients in each group: Treatment Group 1 (TG1) who received sodium valproate (500 to $2500 \mathrm{mg}$ per day) and Treatment Group 2 (TG2) who received olanzapine (5 to $20 \mathrm{mg}$ per day). Sampling technique was simple random sampling. The doses of both the drugs to individual patient, assigned by the consulting Psychiatrist were based on sign and symptoms, clinical response, drug plasma levels and adverse events. These papers were used to randomly allocate the patient in 2 treatment groups at day 0 (baseline). In the present study, out of 74 patients diagnosed with bipolar affective disorder, mania, a total of 60 patients were studied after exclusion and loss to follow up.

Severity of illness was assessed using the 11item,Young Mania Rating Scale (YMRS).YMRS total score $\leq 12$ indicates remission of symptoms and clinical response, defined as $\geq$ $50 \%$ baseline-to-endpoint reduction in YMRS total score.

The data was entered in Microsoft Excel Program (Microsoft Office 2010). Statistical analysis was done using SPSS 20.0 version (Statistical Package for Social Science for Windows Version). Descriptive statistical analysis was done. Results on continuous measurement were presented as Mean \pm SD and results on categorical measurement were presented in number and percentage (\%). To find the significance of study parameters for single group, Paired Samples t-test was used. Comparison was done at $95 \%$ confidence interval of the distribution of the data and $p$ value $<0.05$ was considered statistically significant.

\section{RESULTS}

The mean age of male participants was $39.80 \pm$ 15.85 years and the mean age of female participants was $35.14 \pm 9.40$ years, while the mean age of the study population was $37.08 \pm$ 
12.59 years as depicted in figure 1 . Mean age of the patients in the TG1 was $36.77 \pm 14.258$ and in TG2 the mean age was $37.40 \pm 10.912$ as shown in table 1.

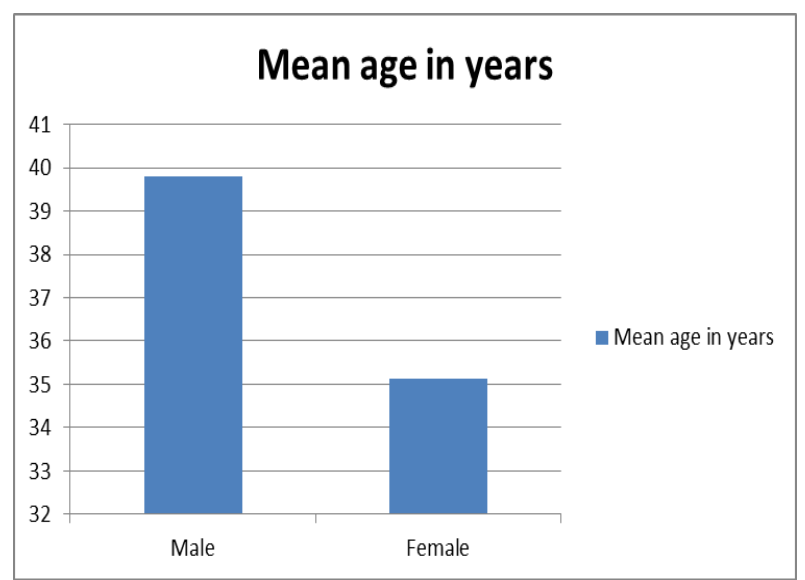

Figure 1: Histogram showing mean age of study population.

Table 1: Mean age of patients in both the treatment group

\begin{tabular}{|l|l|l|}
\hline $\begin{array}{l}\text { Treatment } \\
\text { group }\end{array}$ & $\begin{array}{l}\text { Mean age } \\
\text { (in years) }\end{array}$ & $\begin{array}{l}\text { Standard } \\
\text { deviation }\end{array}$ \\
\hline TG1 & 36.77 & 14.258 \\
\hline TG2 & 37.40 & 10.912 \\
\hline
\end{tabular}

Statistically no significant difference, $\mathrm{p}=0.312$

\section{Starting doses and efficacyof Sodium Valproate}

Patients $(n=30)$ having different scores on the YMRS, were treated with different doses of sodium valproate ranging from $1000 \mathrm{mg} /$ day to $2000 \mathrm{mg} /$ day. Among them 60\% (n=18) were started with $1500 \mathrm{mg} /$ day, $36.66 \%(\mathrm{n}=11)$ were started with $1000 \mathrm{mg} /$ day and 3.33\% (n=1) with $2000 \mathrm{mg} /$ day. In some patients starting with higher doses suggested that upward titration was necessary for anti-manic efficacy. The doses of both the drugs to individual patient, was assigned by the consulting Psychiatrist based on sign and symptoms, clinical response, drug plasma levels and adverse events.
The mean baseline score for all cases treated with sodium valproate on day 0 using the YMRS was $38.87 \pm 3.739$. Overall mean score for all cases on day 7 on YMRS was $33.30 \pm 2.769$, thus YMRS score was reduced by $14.32 \%$ on day 7 . Similarly on day 30 the mean score was $13.90 \pm$ 1.954 which was significantly lower than that compared to the baseline score on day $0 \mathrm{p}=$ 0.00 ). YMRS showed $64.24 \%$ reduction in mean score for all cases from day 0 to day 30 as in table 2.

Table 2: Change in YMRS score from baseline to day 30 in patients receiving sodium valproate

\begin{tabular}{|l|l|l|l|l|l|}
\hline Day & Mean & $\begin{array}{l}\text { Frequenc } \\
\text { (n) }\end{array}$ & $\begin{array}{l}\text { Std. } \\
\text { Deviation }\end{array}$ & $\begin{array}{l}\text { Std. } \\
\text { Error Mean }\end{array}$ & $\begin{array}{l}\text { value } \\
\text { valun }\end{array}$ \\
\hline $\begin{array}{l}\text { Day } \\
0\end{array}$ & 38.87 & 30 & 3.739 & .683 & \\
\hline $\begin{array}{l}\text { Day } \\
7\end{array}$ & 33.30 & 30 & 2.769 & .505 & \multirow{2}{*}{$0.000 *$} \\
\cline { 1 - 5 } $\begin{array}{l}\text { Day } \\
30\end{array}$ & 13.90 & 30 & 1.954 & .357 & \\
\hline \multicolumn{4}{|l|}{ Paired-Samples t-test * Significant difference existed at $\mathrm{p}<0.001}$.
\end{tabular}

\section{Change in the YMRS scores of individual items with sodium valproate}

Maximum reduction in the YMRS scale was seen with the disruptive aggressive behavior (71.08\%) and minimum with insight (14.22\%) over 30 days durations asshown in figure 2 .

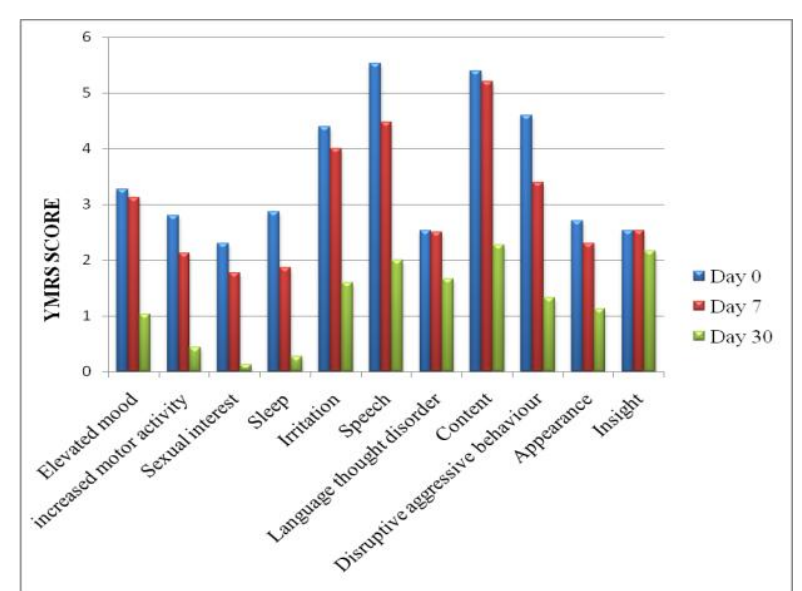

Figure 2: Graph showing the effects of sodium valproate on days 0,7 and 30 . 


\section{Starting doses and efficacy of Olanzapine}

Patients $(n=30)$ having different scores on the YMRS, were treated with different doses of olanzapine ranging from $10 \mathrm{mg} /$ day to 20 $\mathrm{mg} /$ day. Among them 63.33\% $(\mathrm{n}=20)$ were started with $20 \mathrm{mg} /$ day, $23.33 \%(\mathrm{n}=7)$ were started with $15 \mathrm{mg} /$ day and $13.33 \%(\mathrm{n}=4)$ with $10 \mathrm{mg} /$ day. In some patients starting with higher doses suggested that upward titration was necessary for anti-manic efficacy.

The mean baseline score for all cases treated with olanzapine on day 0 using the YMRS was $40.83 \pm 6.502$. Overall mean score for all cases on day 7 on YMRS was $34.03 \pm 4.679$, thus YMRS score was reduced by $16.85 \%$. Similarly on day 30 the mean score was $14.47 \pm 2.837$, which was significantly lower than that compared to the baseline score on day $0(\mathrm{p}=0.00)$. YMRS showed $64.56 \%$ reduction in mean score for all cases from day 0 to day 30 .

Table 3: Change in YMRS score from baseline to day 30 in patients receiving olanzapine

\begin{tabular}{|c|c|l|l|l|l|}
\hline Day & Mean & $\begin{array}{l}\text { Frequency } \\
\text { (n) }\end{array}$ & $\begin{array}{l}\text { Std. } \\
\text { Deviatior }\end{array}$ & $\begin{array}{l}\text { Std. } \\
\text { Error Meal }\end{array}$ & $\begin{array}{l}\text { p- } \\
\text { value }\end{array}$ \\
\hline $\begin{array}{c}\text { Day } \\
0\end{array}$ & 40.83 & 30 & 6.502 & 1.187 & \\
\cline { 1 - 4 } $\begin{array}{c}\text { Day } \\
7\end{array}$ & 34.03 & 30 & 4.679 & .854 & \multirow{2}{*}{$0.000^{*}$} \\
\cline { 1 - 4 } $\begin{array}{c}\text { Day } \\
30\end{array}$ & 14.47 & 30 & 2.837 & .518 & \\
\hline
\end{tabular}

Paired-Samples t-test * Significant difference existed at $\mathrm{p}<0.001$

\section{Change in the YMRS scores of individual items with olanzapine}

Maximum reduction in the YMRS scale was seen with the disruptive aggressive behavior (77.37\%) and minimum with insight (22.29\%) over 30 days durations as depicted by figure 3 .

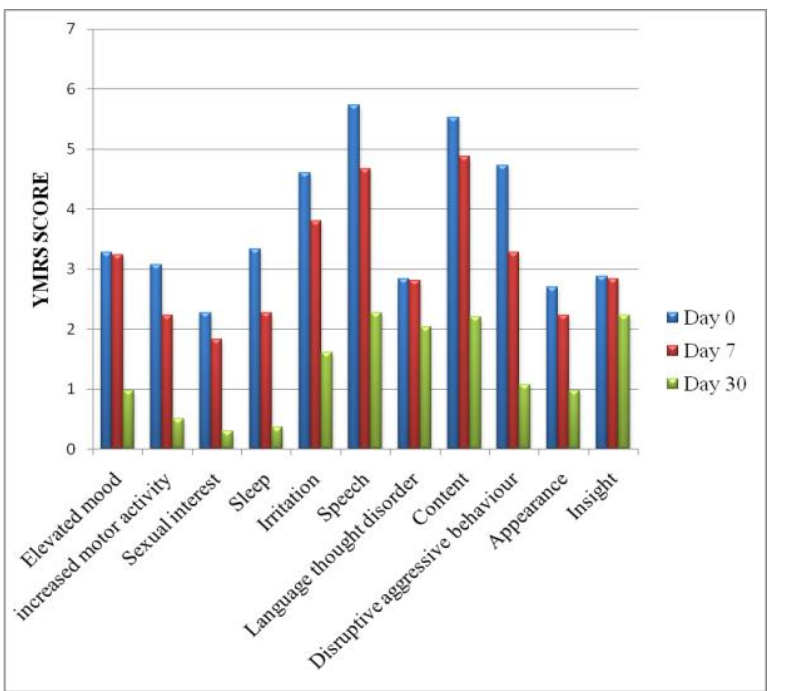

Figure 3: Graph showing effects of Olanpine on day 0, 7 and 30.

Table 4: Mean overall reduction in YMRS by both drugs

\begin{tabular}{|l|l|l|l|}
\hline Drug Group & $\begin{array}{l}\text { YMRS } \\
\text { on day 0 } \\
\text { (Mean } \pm \text { SD) }\end{array}$ & $\begin{array}{l}\text { YMRS } \\
\text { on day 7 } \\
\text { (Mean } \pm \text { SD) }\end{array}$ & $\begin{array}{l}\text { YMRS } \\
\text { on day 30 } \\
\text { (Mean } \pm \text { SD) }\end{array}$ \\
\hline $\begin{array}{l}\text { SODIUM } \\
\text { VALPROATE }\end{array}$ & $38.87 \pm 3.739$ & $33.30 \pm 2.769$ & $13.90 \pm 1.954$ \\
\hline OLANZAPINE & $40.83 \pm 6.502$ & $34.03 \pm 4.679$ & $14.47 \pm 2.837$ \\
\hline
\end{tabular}

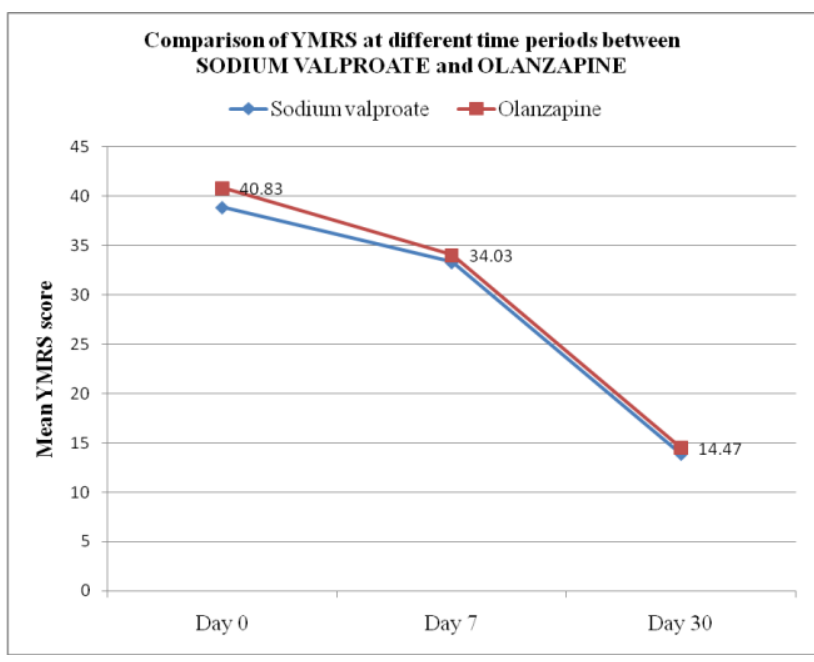

Figure 4: Graph showing mean YMRS score at baseline, day 7 and at day 30 of treatment with sodium valproate and olanzapine.

The mean baseline YMRS score for all cases on sodium valproate $(\mathrm{n}=30)$ on day 0 was $38.87 \pm$ $3.73,33.30 \pm 2.769$ on day 7 and was reduced to 
$13.90 \pm 1.95(\mathrm{p}=0.371)$ on day 30 . Similarly, the mean baseline YMRS score for all cases on olanzapine $(\mathrm{n}=30)$ on day 0 was $40.83 \pm 6.50$, $34.03 \pm 4.679$ on day 7 and was reduced to $14.47 \pm 2.83(\mathrm{p}=0.371)$ on day 30 , as shown in table 4 and figure 4 .

\section{DISCUSSION}

The emphasis of the treatment of bipolar disorder, mania is on effective management of the long-term course of the illness, which consists of medications called mood stabilizers used to prevent or control episodes of mania or depression. The goal of treatment is not to cure the disorder but rather to control the symptoms and the course of the disorder.

The present study was conducted to compare the efficacy of sodium valproate (500$2000 \mathrm{mg} /$ day) and olanzapine $(5-20 \mathrm{mg} /$ day) in the treatment of bipolar affective disorder, mania. A total of 60 patients, 18-70 years old were divided into $25(41.7 \%)$ and 35 (58.3\%) females. The efficacy of both the test drugs were assessed and recorded at baseline, day 7 and day 30 using Young Mania Rating Scale (YMRS).

In this study mean age of patients enrolled in the sodium valproate group was 36.77 years while in olanzapine group it was 37.40 years. The mean age of the patients in both the groups were not statistically significantly different $(p=$ 0.312). Age distribution was similar in both the treatment groups ( $\mathrm{p}=0.312$ on Chi-square test). The mean age of patients diagnosed with bipolar disorder, mania was 39.80 years which was consistent with the mean age of studies conducted by Tohen et al (2002) and Tohen et al (2003).

Females were the predominant sex $58.3 \%$ $(n=35)$, followed by males $41.7 \%(n=25)$ of the total study population. There was no significant difference in the sex of the patents in the two treatment groups ( $\mathrm{p}=0.793$ on Chi-square test). Similar predominance of females was also seen in studies conducted by Tohen et al (2002) (female 57\%) and Tohen et al (2003) (female= $57.4 \%)$.

In this study, flexibly dosed olanzapine (5-20 $\mathrm{mg} /$ day) to sodium valproate $(500-2500$ $\mathrm{mg} /$ day) for manic episodes of bipolar disorder was used. The primary efficacy instrument was the YMRS; a prioriprotocol- defined threshold scores were $\geq 20$ for inclusion, $\leq 12$ for remission and $\geq 15$ for relapse. The study design, assessment scale as YMRS and duration of assessment was similar to that conducted by Tohen et al (2002), Tohen et al (2003), Niufan et al (2008) and the assessment scale used was YMRS similar to assessment scales used by Tohen et al (2002), Tohen et al (2003), Pope et al (1991), Müller-Oerlinghausen et al (2000), Cazorla et al (2013) and Niufan et al (2008).

\section{Sodium valproate as an anti-manic agent}

Sodium valproate has been shown as a promising agent in reducing the symptoms of mania by reducing the assessment scale scores in studies conducted by Ozcan et al (2001), Pope et al (1991) and Tariot et al (2001).

\section{Olanzapine as an anti-manic agent}

Similarly OLANZAPINE has been proved as an anti-manic agent by studies conducted by Poo et al (2014), Niufan et al (2008), Cazorla et al (2013).

\section{Efficacy of sodium valproate versus olanzapine}

Change in total YMRS scores from baseline (day 0 ) to day 7 and day 30 after intervention with sodium valproate and olanzapine was significantly changed showing that both the drugs were effective in reducing the 
psychopathology. Both sodium valproate and olanzapine were as effective as each other in the study conducted by Zajecka et al (2002), Narsimhan et al (2007).

Similarly, a 12-week, double-blind, doubledummy, randomized clinical trial by Reviki et al (2003) showed that sodium valproate and olanzapine have similar short-term effects on clinical or Health Related Quality of Life (HRQL) outcomes in bipolar disorder subjects.

However, the findings in this study are in contradiction to the studies conducted by Tohen et al (2002) and Tohen et al (2003), which suggest that olanzapine had a greater efficacy than sodium valproate in treatment of bipolar disorder, mania.

There are also studies which support the use of combination therapy of sodium valproate and olanzapine in the treatment of bipolar disorder, mania. Studies conducted by Baker et al (2004) and Bai et al (2013) suggested that the use of combination therapy had a greater efficacy in the reduction of rating scores of mania.

In this study, out of the 11 items of YMRS, maximum reduction was seen in the item disruptive aggressive behavior (71.08\%) and minimum reduction was seen in insight (14.22\%) from baseline to day 30 with sodium valproate in TG1. Similarly for olanzapine group (TG2) maximum reduction was seen in disruptive aggressive behavior (26.08\%) with no reduction in insight.

Overall, the highest reduction was seen in disruptive aggressive behavior (74.30\%) and minimum reduction was seen in insight (18.51\%) from baseline to day 30 in both the treatment groups, which is consistent with the findings of studies conducted by Cazorla et al
(2013), Tohen et al (2003) and Pope et al (1991).

In the present study, as assessed by YMRS score, both sodium valproate and olanzapine were effective anti-manic drugs (i.e. significantly lower mean YMRS score; $p<0.05$ ) at day 0, 7 and 30. Overall, the mean decrease in YMRS score was $64.41 \%$, (decrease in YMRS score by sodium valproate was $64.24 \%$ and with olanzapine was $64.56 \%$ ).

\section{CONCLUSION}

As evident from the present study, both the drugs showed significant mean improvement of mania ratings in both the treatment groups. Likewise, the findings of the present study are comparable with other studies and can be used as supportive evidence for further studies. Thus, this study shows that sodium valproate and olanzapine has no statistically significant difference in efficacy in treatment of bipolar affective disorder, mania. An area of potential further studies would be to use larger sample size, use of existing and newer atypical antipsychotics and their combinations, longer duration of assessment in hospitals of different levels including community health centers along with the use of a placebo arm in order to maximize clinical benefit and minimizing adverse events.

\section{ACKNOWLEDGEMENT}

We are deeply thankful for the co-operation and support of the patients who have undergone the sufferings of bipolar affective disorder, mania and the staff members of Department of Pharmacology and Department of Psychiatry, College of Medical Sciences-Teaching Hospital, Bharatpur, Chitwan, Nepal. 


\section{AUTHOR'S CONTRIBUTION}

LC- Drafting of manuscript, data collection, statistical analysis, revision of manuscript finalised; SKS- Concept design, case selection, YMRS score and drug allocation; SMC- Designing and final correction of manuscript.

\section{SOURCE OF SUPPORT: Nil}

\section{CONFLICT OF INTEREST: None declared}

\section{REFERENCES}

1. American Psychiatric Association. Diagnostic and statistical manual of mental disorders. 4th ed. Washington DC: American Psychiatric Association; 2000.

2. World Health Organization. The ICD-10 Classification of mental and behavioural disorders. Geneva: WHO; 1992.

3. Schaffer A, Cairney J, Cheung A, Veldhuizen S, Levitt A. Community survey of bipolar disorder in Canada: lifetime prevalence and illness characteristics. Can J Psychiatry 2006; 51: 9-16.

4. Goodwin FK, Jamison KR. Manic-depressive illness: bipolar and recurrent depression. $2^{\text {nd }}$ ed. New York; Oxford University Press; 2007.

5. World Health Organization. The International statistical classification of diseases and related health problems. Geneva: WHO Press; 2004.

6. Blader JC, Kafantaris V. Pharmacological treatment of bipolar disorder among children and adolescents. Expert Rev Neurother 2007; 7(3): 259-70.

7. Angst J. The emerging epidemiology of hypomania and bipolar II disorder. Journal of Affective Disorders 1998; 50: 143-51.

8. Spearing M. Bipolar Disorder. 2nd ed. Bethesda (MA): National institute of mental health; 2001; 21(4).360-68.

9. Ketter TA, Wang PW, Becker OV, Nowakowska C, Yang YS. The diverse roles of anticonvulsants in bipolar disorders. Annals of Clin Psychiatry 2003; 15(2):95-6.

10. Derry S, Moore RA. Atypical antipsychotics in bipolar disorder: systematic review of randomised trials. BMC Psychiatry 2007;7: 40.
11. Citrome L, Casey DE, Daniel DG, Wozniak P, Kochan LD, Tracy KA. Adjunctive divalproex and hostility among patients with schizophrenia receiving olanzapine or risperidone. Psychiatr Serv 2004; 55(3):290-4.

12. Pope HG, McElroy SL, Keck PE, Hudson JI. Valproate in the treatment of acute mania. A placebo-controlled study. Arch Gen Psychiatry 1991; 48(1):62-8.

13. McDonald WM, Nemeroff CB. The diagnosis and treatment of mania in the elderly. Bull Menninger Clin 1996; 60:174-96.

14. Worrel JA, Marken PA, Beckman SE, Ruehter VL. Atypical antipsychotic agents: a critical review. Am J Health-Syst Pharm 2000; 57: 238-58.

15. Rendell JM, Gijsman HJ, Keck P, Goodwin GM, Geddes JR. Olanzapine alone or in combination for acute mania. Cochrane Database Syst Rev. 2003; 3: 46-87.

16. Young RC, Biggs JT, Ziegler VE, Meyer DA. A rating scale for mania: reliability, validity and sensitivity. British J Psychiatry 1978; 133: 429-35.

17. Tohen $M$, Baker RW, Altshuler LL, Zarate CA Suppes T, Ketter TA, et al. Olanzapine versus divalproex in the treatment of acute mania. Am J Psychiatry 2002; 159(6):1011-7.

18. Tohen M, Ketter TA, Zarate CA, Suppes T, Frye M, Altshuler L, et al. Olanzapine versus divalproex sodium for the treatment of acute mania and maintenance of remission: a 47-week study. Am J Psychiatry 2003; 160(7): 1263-71.

19. Niufan G, Tohen M, Qiuqing A, Fude Y, Pope E, McElroy H, Ming L, Gaohua W, Xinbao Z, Huichun L, Liang S. Olanzapine versus lithium in the acute treatment of bipolar mania: a double-blind, randomized, controlled trial. J Affective Disorders 2008; 105: 101-8.

20. Müller-Oerlinghausen B, Retzow A, Henn FA, Giedke $\mathrm{H}$, Walden J. Valproate as an adjunct to neuroleptic medication for the treatment of acute episodes of mania: a prospective, randomized, double-blind, placebo-controlled, multicenter study. European Valproate Mania Study Group. J Clin Psychopharmacol 2000; 20(2):195-203.

21. Cazorla P, Zhao J, Mackle M, Szegedi A. Asenapine effects on individual Young mania rating scale items in bipolar disorder patients with acute manic or mixed episodes: a pooled analysis. Neuropsychiatric Disease and Treatment 2013; 9: 409-13.

22. Niufan G, Tohen M, Qiuqing A, Fude Y, Pope E, McElroy H, Ming L, Gaohua W, Xinbao Z, Huichun L, Liang S. Olanzapine versus lithium in the 
acute treatment of bipolar mania: a double-blind, randomized, controlled trial. J Affective Disorders 2008; 105: 101-8.

23. Ozcan M, Boztepe AV. Lithium, carbamazepine and valproate in acute mania. Bull Clin Psychopharmacol 2001;11:90-95.

24. Tariot PN, Schneider LS, Mintzer JE, Cutler AJ, Cunningham MR, Thomas JW, Sommerville KW. Safety and tolerability of divalproex sodium in the treatment of signs and symptoms of mania in elderly patients with dementia: results of a doubleblind, placebo-controlled trial. Curr Ther Res 2001; 62(1):51-67.

25. Poo SXW, Agius M atypical anti-psychotics in adult bipolar disorder: current evidence and updates in the nice guidelines. Psychiatria Danubina 2014; 26(1): 322-29.

26. Zajecka JM, Weisler R, Sachs G, Swann AC, Wozniak $\mathrm{P}$, Sommerville KW. A comparison of the efficacy, safety, and tolerability of divalproex sodium and olanzapine in the treatment of bipolar disorder. J Clin Psychiatry 2002; 63: 1148-55.

27. Narasimhan M, Bruce TO, Masand P. Review of olanzapine in the management of bipolar disorders. Neuropsychiatric Disease and Treatment 2007; 3(5): 579-87.

28. Revicki DA, Paramore LC, Sommerville KW, Swann AC, Zajecka JM. Depakote Comparator Study Group. Divalproex sodium versus olanzapine in the treatment of acute mania in bipolar disorder: health-related quality of life and medical cost outcomes. J Clin Psychiatry 2003; 64(3): 288-94.

29. Baker RW, Brown E, Akiskal HS, Calabrese JR, Ketter TA, Schuh LM, et al. Efficacy of olanzapine combined with valproate or lithium in the treatment of dysphoric mania. British J Psychiatry 2004; 185: 472-78.

30. Bai YM, Chang CJ, Tsai SY, Cheng YC, Hsiao MC, Li CT, Tu P, Chang SW, Shen WW, Su TP. Taiwan consensus of pharmacological treatment for bipolar disorder. J Chinese Medical Association 2013; 76(10): 547-56.

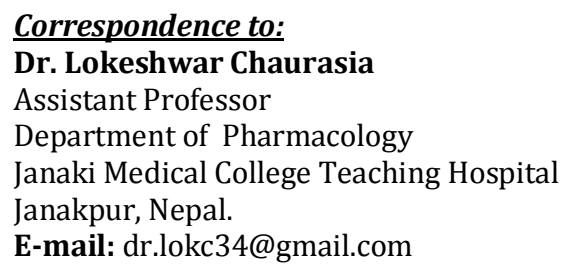

